\title{
Serum Elabela Levels Are Elevated in Patients with Hyperthyroidism
}

\author{
Mahmut Buyuksimsek, ${ }^{1}$ Erdinc Gulumsek, ${ }^{2}$ Muhammed Zubeyir Aslan, ${ }^{3}$ \\ Huseyin Ali Ozturk, ${ }^{3}$ Ahmed Muhammad Bashir, ${ }^{4}$ Yahya Kemal Icen, ${ }^{5}$ \\ Nurettin Ay, ${ }^{3}$ Fettah Acibucu, ${ }^{6}$ Mevlut Koc, ${ }^{5}$ Hilmi Erdem Sumbul ${ }^{3}$ and \\ Tayyibe Saler ${ }^{3}$
}

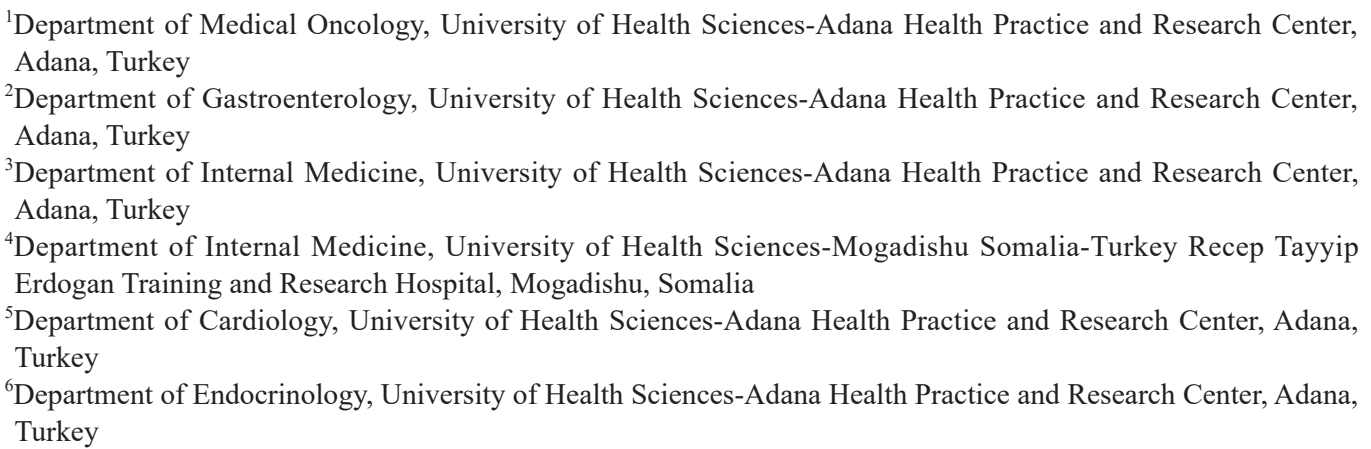

The apelinergic system plays an important role in the modulation of the cardiovascular system via the apelin peptide and the apelin receptor (APJ receptor). Apelin and elabela, also known toddler, are peptide ligands for the apelin receptor. These two peptides show similar biological actions, such as vasodilatation, increased myocardial contractility, angiogenesis, and energy metabolism. However, the serum levels of elabela in patients with hyperthyroidism are not well known. The aim of this study was to investigate the changes in serum elabela levels in patients with hyperthyroidism and its association with hypertension. This cross-sectional study included 74 patients with newly diagnosed hyperthyroidism due to Graves' disease and 20 healthy individuals. Serum elabela levels were measured by enzyme-linked immunosorbent assay. The patients were divided into two groups: hyperthyroid patients without hypertension $(n=51)$ and those with hypertension $(n=23)$. Basal heart rate, serum glucose and highsensitive $C$ reactive protein were significantly higher in hyperthyroid patients with and those without hypertension than in healthy controls ( $p<0.05$ for each). Serum elabela levels were significantly elevated in hyperthyroid patients compared with healthy controls, with higher serum elabela levels found in hyperthyroid patients with hypertension than those without hypertension. Linear regression analysis showed that serum elabela levels were correlated with systolic blood pressure $(p<0.001)$. In conclusion, serum elabela levels were significantly increased in patients with hyperthyroidism, especially in hyperthyroid patients with hypertension. Elevation in serum elabela levels may contribute to alleviation of cardiovascular complications of hyperthyroidism and hypertension.

Keywords: apelinergic system; elabela; hypertension; hyperthyroidism; systolic blood pressure Tohoku J. Exp. Med., 2020 August, 251 (4), 255-261.

\section{Introduction}

The apelinergic system has been reported to play an important role in the modulation of the cardiovascular system via the apelin peptide and the apelin receptor (APJ receptor) (O’Dowd et al. 1993; Perjés et al. 2016). APJ

Received April 9, 2020; revised and accepted July 3, 2020. Published online July 22, 2020; doi: 10.1620/tjem.251.255.

Correspondence: Mahmut Buyuksimsek, M.D., Department of Medical Oncology, University of Health Sciences-Adana Health Practice and Research Center, Dr. Mithat Özsan Bulvarı Kışla Mah. 4522 Sok. No: 1 Yüreğir, Adana 01130, Turkey.

e-mail: mahmutbuyuksimsek@gmail.com

(C)2020 Tohoku University Medical Press. This is an open-access article distributed under the terms of the Creative Commons Attribution-NonCommercial-NoDerivatives 4.0 International License (CC-BY-NC-ND 4.0). Anyone may download, reuse, copy, reprint, or distribute the article without modifications or adaptations for non-profit purposes if they cite the original authors and source properly.

https://creativecommons.org/licenses/by-nc-nd/4.0/ 
receptor was discovered as a putative receptor protein related to angiotensin II type 1 receptor. Apelin and the AJP receptor exert biological actions, such as vasodilatation, increased myocardial contractility, angiogenesis, and energy metabolism. The apelinergic system increases especially for protection in cases of remodeling after myocardial infarction, heart failure and arterial hypertension (Zhang et al. 2018).

Recently, a peptide called elabela, which binds to the same APJ receptor as apelin, has been discovered, and has similar biological actions to apelin (Chng et al. 2013). The gene encoding elabela, or in other name toddler, was predicted to express a 54-amino-acid protein comprising a secretory signal and a 32-amino-acid mature peptide, that has little sequence similarity to apelin. This peptide has been proposed as a second endogenous apelin receptor ligand and is encoded by a gene from a region of the genome previously classified as 'non-coding' (Yang et al. 2015).

Elabela has been reported to be expressed in the endothelium and heart in adults (Chng et al. 2013; Pauli et al. 2014). Studies have reported a relationship between elabela and many cardiovascular conditions and diseases (Zhang et al. 2018). It has been shown that elabela administration in human and animal models causes systemic vasodilatation resulting in a significant decrease in blood pressure (Murza et al. 2016; Yang et al. 2017). Elabela is thought to have this effect by blocking the renin-angiotensin-aldosterone system via the APJ receptor, which is $31 \%$ structurally similar to the angiotensin II type 1 receptor (Zhang et al. 2018).

In the literature the serum elabela level was evaluated in patients with preeclampsia and the elabela level increased in these patients (Liu et al. 2019; Panaitescu et al. 2020). However, only one study reported that the elabela level was decreased in patients with essential hypertension compared to healthy controls ( $\mathrm{Li}$ et al. 2020). This issue is still unclear.

Serum apelin levels have been shown to increase in patients with thyroid hormone disorder (hyperthyroidism or hypothyroidism) compared to healthy controls (Gürel et al. 2015). However, there are no studies investigating the relationship between serum elabela level and hypertension in patients with hyperthyroidism.

We hypothesized that an increase in the activity of the apelinergic system may occur as a result of increased blood pressure in patients with hyperthyroidism, resulting in an increase in serum elabela level. We therefore aimed to investigate the difference in serum elabela levels in healthy controls and in patients with hyperthyroidism and the relationship between serum elabela levels and blood pressure in patients with hyperthyroidism.

\section{Patients and Methods}

\section{Study population}

The cross-sectional study was conducted in a single center between October 2018 - November 2019 at
Department of Internal Medicine, Endocrinology and Cardiology, University of Health Sciences - Adana Health Practice and Research Center. 98 patients with newly diagnosed with hyperthyroidism (Graves' disease) were screened. Twenty-four patients who met the exclusion criteria or did not accept to enroll into the study were excluded during the screening. Therefore, the study included 74 patients $[10$ males and 64 females with the age of $46.7 \pm 10.8$; mean \pm standard deviation (SD)] who were newly diagnosed with hyperthyroidism and 20 healthy control subjects similar in age and gender (6 males and 14 females with the age of $44.7 \pm 9.1$ ) were included in the study group (Fig. 1). The duration of hyperthyroidism before the admission was unknown. Hyperthyroidism and hypertension were newly diagnosed according to the latest published guidelines (Ross et al. 2016; Williams et al. 2018). As a result of repeated office blood pressure measurements (at least in 2 different visits and repeating 2 different measurements); hypertension is defined as office systolic blood pressure values $\geq$ $140 \mathrm{mmHg}$ and/or diastolic blood pressure values $\geq 90$ mmHg (Williams et al. 2018). Patients who received medications that have an effect on the thyroid functional test (such as amiodarone) and glomerular filtration rate $<60$ $\mathrm{mL} / \mathrm{min} / 1.73 \mathrm{~m}^{2}$ or $>30 \mathrm{mg} / \mathrm{L}$ proteinuria, patients with secondary hypertension, diabetes mellitus, renal artery stenosis, moderate or severe valvular heart disease, known heart failure and nephrectomy were excluded from the study.

History was taken and detailed physical examinations were performed. The demographic data were recorded. Heart rate, and systolic and diastolic blood pressure were measured. The weight and height of all cases were measured and body mass index (BMI) was calculated.

This study followed the recommendations of the ethics principles published in the Declaration of Helsinki, developed by the World Medical Association (WMA) and approved by the local ethics committee (Cukurova University Medical Faculty, Ethics Committee). The clinical information for the informed consent was explained to the patients in detail and patients were included in the study after consent was obtained.

\section{Laboratory parameters}

Routine laboratory parameters of all participants [glucose, blood urea nitrogen, creatinine, aspartate aminotransferase, alanine aminotransferase, high-sensitive $\mathrm{C}$ reactive protein (hs-CRP), thyroid stimulating hormone (TSH), free triiodothyronine (T3), free thyroxine (T4) and complete blood count] were analyzed.

Serum elabela levels were determined using commercial kits (Sunred Biological Technology, Shanghai, China). The kit of a double-antibody sandwich enzyme-linked immunosorbent assay (ELISA) was used to measure the level of elabela in morning blood samples.

According to the manufacturer; this assay has interassay coefficients of variation less than $12 \%$ and intra-assay 


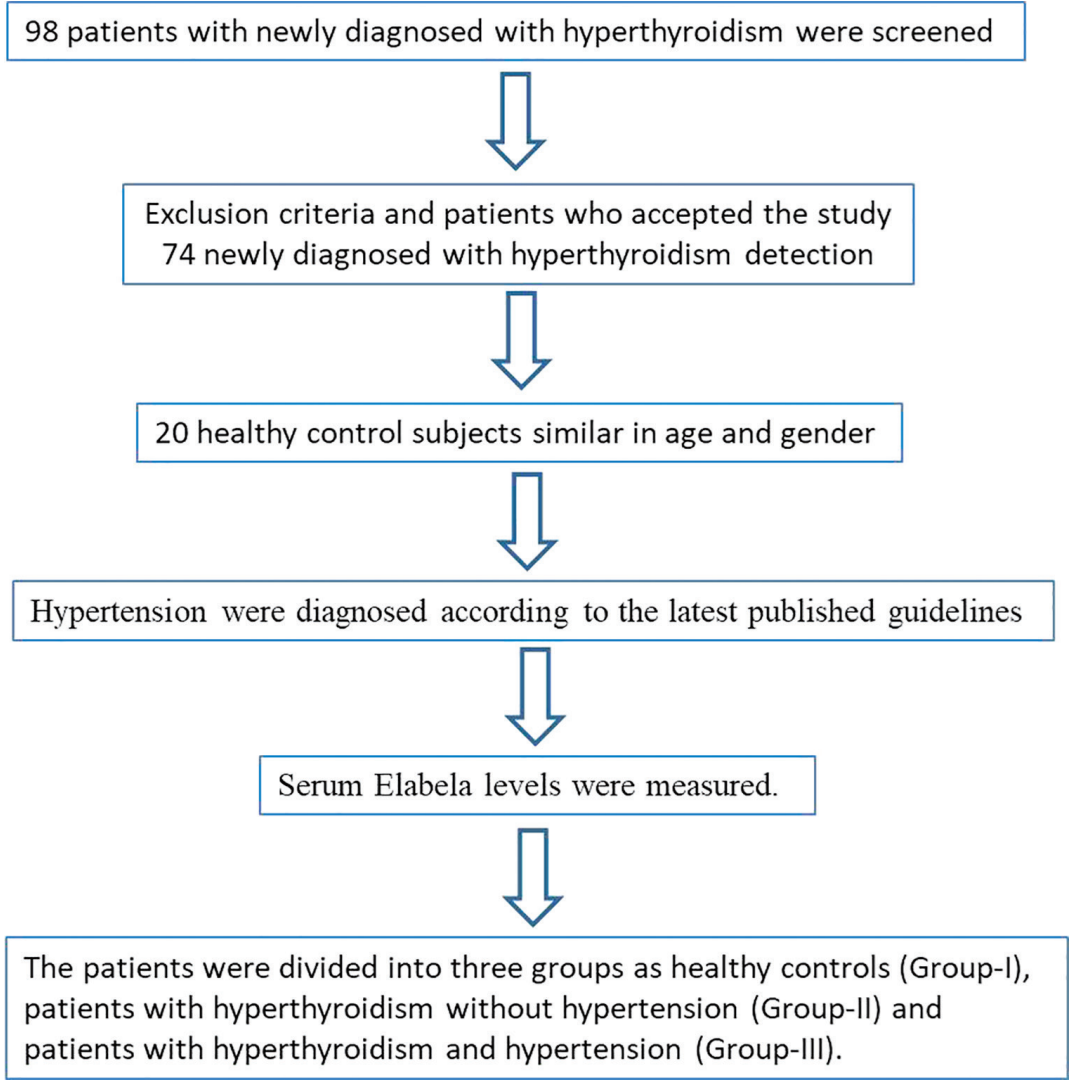

Fig. 1. The flow diagram figure for the study participants.

coefficients of variation of less than $10 \%$. All of the above tests were performed from blood samples that were taken at the 24th hour of hospital admission.

\section{Statistical analysis}

All statistical analyzes were performed using SPSS 22.0 (Chicago, IL, USA) statistical software package. The Kolmogorov-Smirnov test was used to determine whether the distribution of continuous variables was normal or not. Continuous variables in the group data were expressed as mean \pm SD. Continuous variables were compared by oneway ANOVA or Kruskal-Wallis test. For data with normal distribution, Scheffe test and Games-Howells test were used for multiple comparisons of groups with respect to homogeneity of variances. For abnormal distributed data, Bonferroni-adjusted Mann Whitney U test was used for multiple comparisons of groups. In comparison of categorical variables, chi-square $\left(\chi^{2}\right)$ test was used. The existence of relationship between countable parameters was evaluated by Pearson's and Spearman's correlation analysis. Multivariate linear regression analysis was performed for the serum elabela levels, which were significant in the univariate analysis. Statistical significance was accepted if $p<$ 0.05 .

\section{Results}

All patients included in the study were divided into three groups according to thyroid function test and presence of hypertension; healthy controls, hyperthyroid patients without hypertension, and hyperthyroid patients with hypertension.

When the demographic findings of the study groups were compared; systolic and diastolic blood pressure values were highest in hyperthyroid patients with hypertension, and systolic and diastolic blood pressure values of hyperthyroid patients with hypertension were significantly higher than healthy controls, and hyperthyroid patients without hypertension. Basal heart rate was statistically higher in hyperthyroid patients with or without hypertension than healthy controls. Basal heart rate was similar between hyperthyroid patients with and without hypertension (Table 1). Age, gender and BMI were not significantly different among the 3 groups (Table 1).

Laboratory data revealed that serum glucose, hs-CRP, free T3, free T4 levels were significantly higher and TSH levels were significantly lower in hyperthyroid patients with and without hypertension than healthy controls. The same laboratory parameters were similar between hyperthyroid patients with and without hypertension. Serum elabela levels were significantly elevated in hyperthyroid patients with or without hypertension than healthy controls, indicating that patients with hyperthyroidism showed higher serum elabela levels. In addition, serum elabela levels were significantly elevated in hyperthyroid patients with hyper- 
Table 1. Demographic and laboratory findings according to study groups.

\begin{tabular}{|c|c|c|c|c|}
\hline Variable & $\begin{array}{l}\text { Healthy } \\
\text { controls } \\
n=20\end{array}$ & $\begin{array}{l}\text { Hyperthyroid patients } \\
\text { without hypertension } \\
\qquad \mathrm{n}=51\end{array}$ & $\begin{array}{l}\text { Hyperthyroid patients } \\
\text { with hypertension } \\
n=23\end{array}$ & $\mathrm{p}^{*}$ \\
\hline Age (year) & $44.7 \pm 9.1$ & $45.4 \pm 10.1$ & $47.8 \pm 11.3$ & 0.286 \\
\hline Gender (female) & 14 & 43 & 21 & 0.069 \\
\hline Systolic blood pressure (mmHg) & $110 \pm 16^{\alpha}$ & $115 \pm 17^{¥}$ & $152 \pm 15$ & $<0.001$ \\
\hline Diastolic blood pressure (mmHg) & $72 \pm 5.9^{\alpha}$ & $74 \pm 8.6^{¥}$ & $94 \pm 11$ & $<0.001$ \\
\hline Basal heart rate (pulse/minute) & $68 \pm 8.2^{\alpha, \beta}$ & $85 \pm 12$ & $93 \pm 16$ & $<0.001$ \\
\hline Body mass index $\left(\mathrm{kg} / \mathrm{m}^{2}\right)$ & $27.5 \pm 1.6$ & $28.1 \pm 1.8$ & $27.9 \pm 2.2$ & 0.414 \\
\hline White blood cell $(\mu \mathrm{L})$ & $6.45 \pm 1.54$ & $6.63 \pm 1.65$ & $7.31 \pm 2.13$ & 0.082 \\
\hline Hemoglobin $(\mathrm{g} / \mathrm{dL})$ & $12.9 \pm 1.6$ & $12.6 \pm 1.27$ & $13.2 \pm 1.84$ & 0.229 \\
\hline Glucose (mg/dL) & $92.2 \pm 7.4^{\alpha, \beta}$ & $101 \pm 13$ & $104 \pm 17$ & $<0.001$ \\
\hline Blood urea nitrogen (mg/dL) & $29.5 \pm 3.96$ & $32.7 \pm 18.5$ & $35.3 \pm 19.1$ & 0.253 \\
\hline Creatinine $(\mathrm{mg} / \mathrm{dL})$ & $0.65 \pm 0.07$ & $0.74 \pm 0.54$ & $0.79 \pm 0.65$ & 0.377 \\
\hline Aspartate aminotransferase $(\mathrm{u} / \mathrm{L})$ & $18.9 \pm 3.17$ & $18.2 \pm 4.05$ & $20.6 \pm 8.1$ & 0.143 \\
\hline Alanine aminotransferase $(\mathrm{u} / \mathrm{L})$ & $14.0 \pm 2.88$ & $13.4 \pm 4.9$ & $16.1 \pm 10$ & 0.098 \\
\hline hs-CRP (mg/L) & $0.42 \pm 0.32^{\alpha, \beta}$ & $1.54 \pm 2.53$ & $1.69 \pm 2.22$ & 0.013 \\
\hline Free T3 (ng/L) & $3.45 \pm 0.58^{\alpha, \beta}$ & $5.97 \pm 1.58$ & $6.78 \pm 4.52$ & $<0.001$ \\
\hline Free T4 (ng/dL) & $0.82 \pm 0.08^{\alpha, \beta}$ & $2.11 \pm 0.87$ & $2.34 \pm 1.08$ & $<0.001$ \\
\hline Thyroid stimulating hormone $(\mathrm{mUI} / \mathrm{L}) * *$ & $1.89 \pm 0.64$ & $<0.01$ & $<0.01$ & - \\
\hline Elabela level (ng/mL) & $1.86 \pm 0.60^{\alpha, \beta}$ & $9.73 \pm 1.52^{¥}$ & $14.2 \pm 2.05$ & $<0.001$ \\
\hline
\end{tabular}

The values were shown as mean \pm standard deviation.

$\alpha=$ the significant difference between healthy controls and hyperthyroid patients with hypertension $(\mathrm{p}<0.05)$.

$\beta=$ the significant difference between healthy controls and hyperthyroid patients without hypertension $(\mathrm{p}<0.05)$.

$¥=$ the significant difference between hyperthyroid patients without hypertension and hyperthyroid patients with hypertension $(\mathrm{p}<0.05)$.

hs-CRP, high-sensitive $\mathrm{C}$ reactive protein.

*The $\mathrm{p}$ values less than 0.05 in the ANOVA test are shown in bold.

**The ANOVA test was not performed concerning thyroid stimulating hormone, because the levels were $<0.01 \mathrm{mUI} / \mathrm{L}$ in hyperthyroid patients with and without hypertension.

tension compared to hyperthyroid patients without hypertension, indicating that the presence of hypertension elevates further serum elabela levels in patients with hyperthyroidism (Table 1, Fig. 2). All other laboratory parameters were similar among the 3 groups (Table 1).

Correlation analysis was performed between serum elabela and other demographic, clinical and laboratory parameters (Table 2). Linear regression analysis was performed by including the parameters that were significant in the correlation analysis to determine the parameter most closely related to the serum elabela level. As a result of this analysis, it was found that systolic blood pressure was closely and positively correlated with serum elabela level (Table 2, Fig. 3).

\section{Discussion}

The most important finding of our study was that serum elabela levels were significantly increased in patients with hyperthyroidism compared to healthy controls. To our knowledge, this is the first study to show that the serum elabela value is increased in patients with hyperthyroidism. Another important finding of our study was that serum elabela levels were higher in hyperthyroid patients with hyper- tension compared to normotensive hyperthyroid patients. In addition, serum elabela levels were positively correlated with systolic blood pressure.

Several parameters have been evaluated in the studies about the effects of the apelinergic system and related peptides on the cardiovascular system. It has been reported that the apelinergic system causes improvement especially in diseases causing cardiac hypertrophy and fibrosis processes such as hypertension, heart failure and myocardial infarction (Zhang et al. 2018). All of these positive and cardiovascular protective effects are thought to be a method for treatment (Yang et al. 2015). Although there are many studies on cardiovascular diseases such as serum elabela or apelin level related to hypertension, heart failure and myocardial infarction (Dai et al. 2006; Simpkin et al. 2007), there are no studies on serum elabela level in patients with hyperthyroidism. As it is known, hypertension is very common in patients with hyperthyroidism and is associated with left ventricular hypertrophy (Tamer et al. 2005; Prisant et al. 2006).

For the first time in our study, serum elabela levels were found to be significantly increased in patients with hyperthyroidism with and without hypertension, and be 


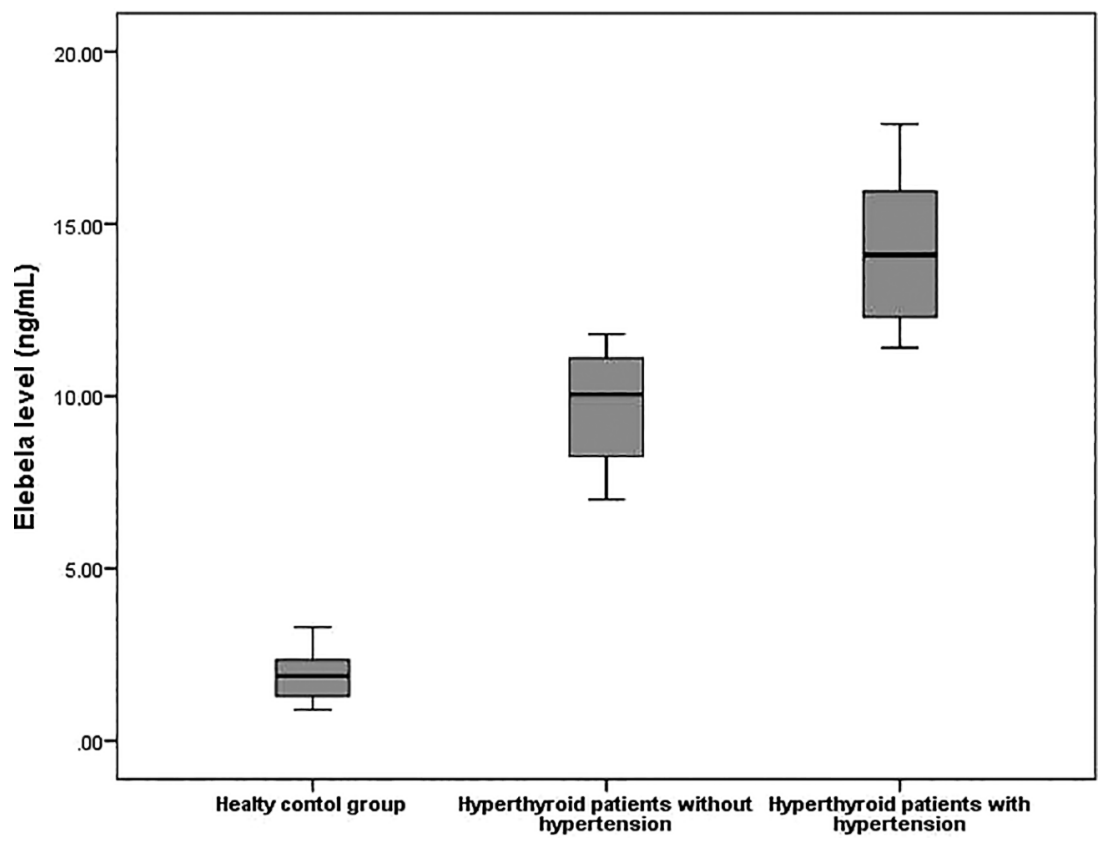

Fig. 2. The Box plot graphic showed that serum elabela levels in study groups.

Serum elabela levels were significantly elevated in hyperthyroid patient groups compared with healthy controls. In addition, serum elabela levels were significantly elevated in hyperthyroid patients with hypertension compared to those without hypertension.

very closely and positively related to systolic blood pressure. This important finding obtained in our study indicates that the serum elabela level was increased by direct activation of the apelinergic system, which was caused by the vascular and cardiac response to the increased thyroid hormones in patients with hyperthyroidism. Since there is no study evaluating the serum elabela levels in patients with hyperthyroidism, the data in our study could not be compared with other studies. However, in the literature, serum apelin levels have been reported to be increased in patients with thyroid dysfunction such as hyperthyroidism or hypothyroidism compared to healthy controls (Gürel et al. 2015). Cardiovascular adverse events such as increased arterial stiffness (Resnick and Laragh 1982), systolic hypertension (Prisant et al. 2006), left ventricular hypertrophy (Tamer et al. 2005), and heart failure (Woeber 1992; Klein and Ojamaa 2001) occur in patients with hyperthyroidism. Previous studies have shown that elabela and apelin were synthesized to slow down these cardiovascular adverse events. Serum elabela levels may be increased as a result of increased activity of the apelinergic system in order to slow down or regress the increased negative vascular and cardiac effects in patients with hyperthyroidism.

Hypertension secondary to hyperthyroidism is one of the important and curable causes, and the frequency of hypertension in patients with hyperthyroidism is approximately $20-30 \%$ (Prisant et al. 2006). In our study, hypertension was detected in $31 \%$ patients with hyperthyroidism and this finding was consistent with the literature. When patients with hyperthyroidism are grouped as with and without hypertension, serum elabela levels were significantly higher in hyperthyroid patients with hypertension. This supported our hypothesis that serum elabela levels were increased further in response to hypertensive status. As it is known, systolic blood pressure increases in patients with hyperthyroidism and systolic hypertension occurs (Prisant et al. 2006). In our study, the positive and close relationship between serum elabela level and systolic blood pressure strengthened this relationship. However, there is no clear information in the literature regarding the change of apelin and elabela levels in patients with hypertension. In a study about the patients with preeclampsia, it was found that serum elabela level was increased (Liu et al. 2019; Panaitescu et al. 2020).

It has been reported that serum apelin levels are increased in patients with hyperthyroidism or hypothyroidism compared to healthy controls (Gürel et al. 2015). In our study, it was found that serum elabela level was 7 times higher in hyperthyroid patients with hypertension than in healthy controls. However, in our study, it was not clear whether the elevated serum elabela level was secondary to hypertension development, or was related to hyperthyroidism. However, it should be taken into consideration that serum elabela level was elevated in hyperthyroid patients without hypertension.

Only one study has shown that serum elabela levels were lower in patients with essential hypertension than the control group (Li et al. 2020). However, 2 other studies, in which patients with preeclampsia were included, reported that the serum elabela levels were higher in patients with preeclampsia than in the control group. Hypertension pathophysiology is different between essential hypertension 
Table 2. The parameters associated with serum Elabela level and linear regression analysis for parameters significantly correlated with serum Elabela.

\begin{tabular}{lrrrr}
\hline & \multicolumn{2}{c}{ Univariate analyze } & \multicolumn{2}{c}{ Multivariate analyze } \\
\cline { 2 - 5 } & \multicolumn{1}{c}{$\mathrm{p}$} & $\mathrm{r}$ & $\mathrm{p}$ & $\beta$ \\
\hline Age (year) & 0.033 & -0.195 & 0.453 & 0.031 \\
Systolic blood pressure (mmHg) & $<0.001$ & 0.625 & $<0.001$ & 0.375 \\
Diastolic blood pressure (mmHg) & $<0.001$ & 0.493 & 0.174 & 0.054 \\
Basal heart rate (pulse/minute) & $<0.001$ & 0.522 & 0.111 & 0.061 \\
Body mass index (kg/m²) & 0.012 & 0.211 & 0.267 & 0.032 \\
Fasting plasma glucose (mg/dL) & $<0.001$ & 0.461 & 0.456 & 0.030 \\
Blood urea nitrogen (mg/dL) & 0.020 & 0.261 & 0.152 & 0.062 \\
Creatinine (mg/dL) & 0.010 & 0.205 & 0.052 & 0.095 \\
hs-CRP (mg/l) & $<0.001$ & 0.367 & 0.324 & 0.045 \\
Free T3 (ng/L) & $<0.001$ & 0.568 & 0.423 & 0.207 \\
Free T4 (ng/dL) & $<0.001$ & 0.680 & 0.232 & 0.185 \\
\hline
\end{tabular}

$R_{A d j u s t e d}^{2}=0.806$ in multivariate analyses.

hs-CRP, high-sensitive $\mathrm{C}$ reactive protein.

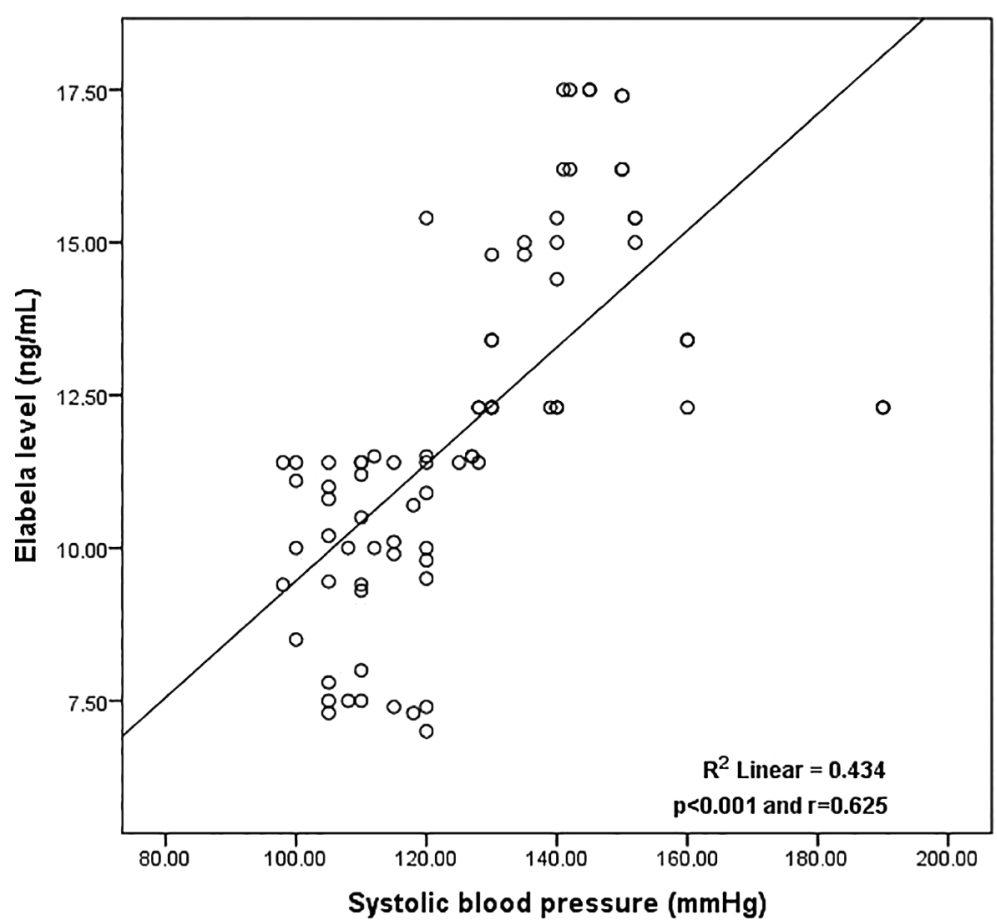

Fig. 3. Scatter plot diagram of the relationship between serum elabela levels and systolic blood pressure.

Systolic blood pressure was closely and positively correlated with serum elabela levels $(r=0.625, p<0.001)$.

and preeclampsia (Liu et al. 2019; Panaitescu et al. 2020). Hypertension pathophysiology in patients with hyperthyroidism may be different from that of both diseases. In our study serum elabela levels were higher in hyperthyroid patients with and without hypertension. In another study, the increase in serum apelin level in patients with thyroid diseases also supported our findings (Gürel et al. 2015). In addition, the serum elabela level was higher in patients with hyperthyroidism and hypertension. It is not correct to compare the results of our study with the study about essential hypertension. However, in our study, we hypothesize that the reason for the increase in serum elabela level in patients with hyperthyroidism and hypertension should be that the apelinergic system gained preventive activity in order to decrease the increased systolic and diastolic blood pressure, and therefore the serum elabela level was increased in order to protect or lower the blood pressure.

Although biochemical measurements were made in our study, there was no study on the level of APJ receptor from the tissue samples. A similar finding could be more 
significant at the vascular endothelial level. In our study, although there was a relationship between serum elabela levels, and TSH and systolic blood pressure levels, ventricular wall thickness and vascular tonus were not measured. More meaningful results could also be obtained if left ventricular hypertrophy evaluation was done.

In our study, elabela level was evaluated before the treatment only in patients with hyperthyroidism; therefore, a more significant result could be obtained if the serum level was examined after the treatment of hyperthyroidism. New studies with the same characteristics of our study will be planned in which echocardiography and vascular tonus were evaluated, tissue samples were examined and elabela levels were evaluated after the treatment of hyperthyroidism.

In conclusion, serum elabela levels were increased in patients with hyperthyroidism compared with healthy controls. This may be a sign of upregulation in the apelinergic system to produce increased cardiovascular effects in response to cardiac and vascular involvement in patients with hyperthyroidism. Elevation in serum elabela levels may be an early sign of hypertension development due to vascular adverse effects of hyperthyroidism.

\section{Conflict of Interest}

The authors declare no conflict of interest.

\section{References}

Chng, S.C., Ho, L., Tian, J. \& Reversade, B. (2013) ELABELA: a hormone essential for heart development signals via the apelin receptor. Dev. Cell, 27, 672-680.

Dai, T., Ramirez-Correa, G. \& Gao, W.D. (2006) Apelin increases contractility in failing cardiac muscle. Eur. J. Pharmacol., 553, 222-228.

Gürel, A., Doğantekin, A., Özkan, Y. \& Aydın, S. (2015) Serum apelin levels in patients with thyroid dysfunction. Int. J. Clin. Exp. Med., 8, 16394-16398.

Klein, I. \& Ojamaa, K. (2001) Thyroid hormone and the cardiovascular system. N. Engl. J. Med., 344, 501-509.

Li, Y., Yang, X., Ouyang, S., He, J., Yu, B., Lin, X., Zhang, Q. \& Tao, J. (2020) Declined circulating Elabela levels in patients with essential hypertension and its association with impaired vascular function: a preliminary study. Clin. Exp. Hypertens., 42, 239-243.

Liu, Y., Wang, L. \& Shi, H. (2019) The biological function of ELABELA and APJ signaling in the cardiovascular system and pre-eclampsia. Hypertens. Res., 42, 928-934.

Murza, A., Sainsily, X., Coquerel, D., Côté, J., Marx, P., BessererOffroy, É., Longpré, J.M., ,Lainé, J., Reversade, B., Salvail, D., Leduc, R., Dumaine, R., Lesur, O., Auger-Messier, M., Sarret, P., et al. (2016) Discovery and structure-activity relationship of a bioactive fragment of ELABELA that modulates vascular and cardiac functions. J. Med. Chem., 59, 29622972.

O’Dowd, B.F., Heiber, M., Chan, A., Heng, H.H., Tsui, L.C.,
Kennedy, J.L., Shi, X., Petronis, A., George, S.R. \& Nguyen, T. (1993) A human gene that shows identity with the gene encoding the angiotensin receptor is located on chromosome 11. Gene, 136, 355-360.

Panaitescu, B., Romero, R., Gomez-Lopez, N., Pacora, P., Erez, O., Vadillo-Ortega, F., Yeo, L., Hassan, S.S. \& Hsu, C.D. (2020) ELABELA plasma concentrations are increased in women with late-onset preeclampsia. J. Matern. Fetal Neonatal Med., 33, 5-15.

Pauli, A., Norris, M.L., Valen, E., Chew, G.L., Gagnon, J.A., Zimmerman, S., Mitchell, A., Ma, J., Dubrulle, J., Reyon, D., Tsai, S.Q., Joung, J.K., Saghatelian, A. \& Schier, A.F. (2014) Toddler: an embryonic signal that promotes cell movement via Apelin receptors. Science, 343, 1248636.

Perjés, Á., Kilpiö, T., Ulvila, J., Magga, J., Alakoski, T., Szabó, Z., Vainio, L., Halmetoja, E., Vuolteenaho, O., Petäjä-Repo, U., Szokodi, I. \& Kerkela, R. (2016) Characterization of apela, a novel endogenous ligand of apelin receptor, in the adult heart. Basic Res. Cardiol., 111, 2.

Prisant, L.M., Gujral, J.S. \& Mulloy, A.L. (2006) Hyperthyroidism: a secondary cause of isolated systolic hypertension. J. Clin. Hypertens. (Greenwich), 8, 596-599.

Resnick, L.M. \& Laragh, J.H. (1982) PLasma renin activity in syndromes of thyroid hormone excess and deficiency. Life Sci., 30, 585-586.

Ross, D.S., Burch, H.B., Cooper, D.S., Greenlee, M.C., Laurberg, P., Maia, A.L., Rivkees, S.A., Samuels, M., Sosa, J.A., Stan, M.N. \& Walter, M.A. (2016) 2016 American Thyroid Association Guidelines for Diagnosis and Management of Hyperthyroidism and other causes of Thyrotoxicosis. Thyroid, 26, 1343-1421.

Simpkin, J.C., Yellon, D.M., Davidson, S.M., Lim, S.Y., Wynne, A.M. \& Smith, C.C. (2007) Apelin-13 and apelin-36 exhibit direct cardioprotective activity against ischemia-reperfusion injury. Basic Res. Cardiol., 102, 518-528.

Tamer, I., Sargin, M., Sargin, H., Seker, M., Babalik, E., Tekce, M. \& Yayla, A. (2005) The evaluation of left ventricular hypertrophy in hypertensive patients with subclinical hyperthyroidism. Endocr. J., 52, 421-425.

Williams, B., Mancia, G., Spiering, W., Agabiti Rosei, E., Azizi, M., Burnier, M., Clement, D.L., Coca, A., de Simone, G., Dominiczak, A., Kahan, T., Mahfoud, F., Redon, J., Ruilope, L., Zanchetti, A., et al. (2018) 2018 ESC/ESH Guidelines for the management of arterial hypertension. Eur. Heart J., 39, 3021-3104.

Woeber, K.A. (1992) Thyrotoxicosis and the heart. N. Engl. J. Med., 327, 94-98.

Yang, P., Maguire, J.J. \& Davenport, A.P. (2015) Apelin, Elabela/ Toddler, and biased agonists as novel therapeutic agents in the cardiovascular system. Trends Pharmacol. Sci., 36, 560-567.

Yang, P., Read, C., Kuc, R.E., Buonincontri, G., Southwood, M., Torella, R., Upton, P.D., Crosby, A., Sawiak, S.J., Carpenter, T.A., Glen, R.C., Morrell, N.W., Maguire, J.J. \& Davenport, A.P. (2017) Elabela/toddler is an endogenous agonist of the apelin APJ receptor in the adult cardiovascular system, and exogenous administration of the peptide compensates for the downregulation of its expression in pulmonary arterial hypertension. Circulation, 135, 1160-1173.

Zhang, Y., Wang, Y., Lou, Y., Luo, M., Lu, Y., Li, Z., Wang, Y. \& Miao, L. (2018) Elabela, a newly discovered APJ ligand: similarities and differences with Apelin. Peptides, 109, 23-32. 